\title{
HYPERGRAPHS WITH PENDANT PATHS ARE NOT CHROMATICALLY UNIQUE
}

\author{
IOAN TOMESCU \\ Faculty of Mathematics and Computer Science \\ University of Bucharest \\ Str. Academiei, 14 \\ 010014 Bucharest, Romania \\ e-mail: ioan@fmi.unibuc.ro
}

\begin{abstract}
In this note it is shown that every hypergraph containing a pendant path of length at least 2 is not chromatically unique. The same conclusion holds for $h$-uniform $r$-quasi linear 3-cycle if $r \geq 2$.
\end{abstract}

Keywords: sunflower hypergraph, chromatic polynomial, chromatic uniqueness, pendant path.

2010 Mathematics Subject Classification: 05C15; 05C65.

\section{REFERENCES}

[1] C. Berge, Graphs and Hypergraphs (North-Holland, Amsterdam, 1973).

[2] S.A. Bokhary, I. Tomescu and A.A. Bhatti, On the chromaticity of multi-bridge hypergraphs, Graphs Combin. 25 (2009) 145-152. doi:10.1007/s00373-008-0831-7

[3] M. Borowiecki and E. Łazuka, Chromatic polynomials of hypergraphs, Discuss. Math. Graph Theory 20 (2000) 293-301.

doi:10.7151/dmgt.1128

[4] C.Y. Chao and E.G. Whitehead, Jr., On chromatic equivalence of graphs, in: Theory and Applications of Graphs, Y. Alavi and D.R. Lick (Ed(s)), (Lecture Notes Math. 642, New York, Springer (1978)) 121-131.

[5] D. Dellamonica, V. Koubek, D.M. Martin and V. Rödl, On a conjecture of Thomassen concerning subgraphs of large girth, J. Graph Theory 67 (2011) 316331.

doi:10.1002/jgt.20534 
[6] K. Dohmen, Chromatische Polynome von Graphen und Hypergraphen (Dissertation, Düsseldorf, 1993).

[7] P. Erdős and R. Rado, Intersection theorems for systems of sets, J. Lond. Math. Soc. 35 (1960) 85-90. doi:10.1112/jlms/s1-35.1.85

[8] Z. Füredi, On finite set-systems whose intersection is a kernel of a star, Discrete Math. 47 (1983) 129-132. doi:10.1016/0012-365X(83)90081-X

[9] K.M. Koh and K.L. Teo, The search for chromatically unique graphs, Graphs Combin. 6 (1990) 259-285. doi:10.1007/BF01787578

[10] I. Tomescu, Chromatic coefficients of linear uniform hypergraphs, J. Combin. Theory (B) $72(1998)$ 229-235. doi:10.1006/jctb.1997.1811

[11] I. Tomescu, Sunflower hypergraphs are chromatically unique, Discrete Math. 285 (2004) $355-357$. doi:10.1016/j.disc.2004.02.015

[12] I. Tomescu, On the chromaticity of sunflower hypergraphs $S H(n, p, h)$, Discrete Math. 307 (2007) 781-786. doi:10.1016/j.disc.2006.07.026

[13] I. Tomescu and S. Javed, On the chromaticity of quasi linear hypergraphs, Graphs Combin. 29 (2013) 1921-1026. doi:10.1007/s00373-012-1232-5

[14] M. Walter, Some results on chromatic polynomials of hypergraphs, Electron. J. Combin. 16 (2009) R94.

Received 7 May 2012

Revised 11 October 2012

Accepted 15 October 2012 